\title{
Keloids: Fundamental principles and prospects (Review)
}

\author{
MATTHIAS GIERINGER ${ }^{1}$, KATHARINE ELLIOTT ${ }^{2}$, JAN GOSEPATH ${ }^{1}$ and RAMIN NAIM ${ }^{1}$ \\ ${ }^{1}$ Department of Otolaryngology, Head and Neck Surgery, HSK, Dr Horst Schmidt Kliniken GmbH, \\ 65199 Wiesbaden, Germany; ${ }^{2}$ Royal Free Hospital, Hampstead, London NW3 2QG, UK
}

Received June 29, 2009; Accepted September 22, 2009

DOI: $10.3892 / \mathrm{mmr}+00000212$

\begin{abstract}
Wound healing is a very complex process of interactions between different cells, growth factors, blood elements and extracellular matrix. Keloids represent one of the possible complications in the fundamental process of cutaneous wound repair. Despite all efforts, keloids remain a therapeutic challenge since no treatment is as yet considered $100 \%$ effective. Growth factors, discovered in the late 1970s, have been shown to influence dermal regeneration. However, the exogenous application of growth factors to chronic wounds has not proven to be effective in healing them. Additionally, genetic analysis has not revealed any single gene that might cause keloids; as such, classic gene therapy is not a feasible option for the treatment of keloids. A new approach is so-called somatic gene therapy. This review provides an overview of the fundamentals of wound healing and of keloids, and presents new possibilities that may improve cutaneous wound repair.
\end{abstract}

\section{Contents}

1 Introduction

2. Wound healing

3. First to third day: exudative dates (phase of physiological inflammation)

4. Fourth to seventh day: phase of proliferation (i.e., phase of formation of granulation tissue)

5. Classification of scars

6. Incidence of keloids

7. Histology of keloids

8. Growth factors and cytokines

9. Fundamentals of prevention and therapy

10. Prospects

Correspondence to: Dr Matthias Gieringer, Klinik für Hals-, Nasen- und Ohrenheilkunde, Kopf- und Halschirurgie, HSK, Dr Horst Schmidt Kliniken GmbH, Ludwig-Erhard-Str. 100, 65199 Wiesbaden, Germany

E-mail: mkgieringer@gmail.com

Key words: keloids, cytokines, growth factor

\section{Introduction}

The complete restoration of cutaneous skin architecture is the optimal outcome of skin repair, but only fetal skin can heal in this way. Scars are the end point of the normal continuum of tissue repair. If fetal scarless wounds represent one end of the tissue repair spectrum, keloids represent the other end. In addition to the considerable functional loss and unwanted cosmetic result, keloids can cause psychosocial effects including a loss of self esteem, as well as social stigmatisation leading to a dimished quality of life $(1,2)$. The prevention and treatment of keloids are particularly characterised by downright polypragmacy, leading to an elevated rate of recurrence. The last two decades have seen an expansion in knowledge related to wound healing. Currently, wound healing is understood to be a sequence of thousands of individual steps from wound formation to closure, the result of both local cellular interactions and the regulation of systemic response. Coordination occurs through communicating molecules, known as cytokines and growth factors $(3,4)$. Despite recent advances, science is still only skimming the surface of the processes involved in wound healing. Currently, it is the comprehension of the fundamental molecular principles regarding both normal and disturbed wound healing that provides effective therapeutic options.

This article discusses the fundamentals of wound healing, the classification of scars, and the incidence and histology of keloids, as well as the fundamentals of their prevention and therapy. As a specific topic, the role of growth factors in wound healing is highlighted. Finally, future prospects in the treatment of abnormal scarring are surveyed.

\section{Wound healing}

A wound is the interruption of connected body tissue either with or without loss of substance. Causes range from various physical or chemical insults to inflammation and ischaemia. A cutaneous wound is defined as a cut through the skin. The terms abrasion or excoriation of skin refer to injury of the non-vascular epidermis. These forms of wounds heal without leaving a scar. The most pronounced type of skin wound is that of complete skin damage. In this latter category of skin wound, repair results in a mass of fibrotic tissue called a scar. This appears as a fine line, without function, which is often aesthetically displeasing. A wide range of problems exist in wound healing, from chronic wounds without wound closure to hypertropic scars and keloids. The repair of wounds is one of 
the most complex processes known. It is characterised by the interaction between a series of factors, including hormones, blood components and secondary messengers, which occur in a precise sequence in the different layers of the skin. These complicated interactions are mediated by interacting molecules, both mediators and receptors, known as growth factors. Growth factors are synthesised and secreted by many types of cells involved in tissue repair, including platelets, inflammatory cells, fibroblasts, epithelial cells and vascular endothelial cells $(5,6)$. If the restoration of the injured tissue is succesful and healing by restoration or even by fibrosis takes place, this process must be shut down by programmed cell death, called apoptosis. Wound healing follows a specific time sequence. Put simply, the very complex repair processes are sub-divided into three phases. Due to their complexity, the three processes are described below in simplified form.

\section{First to third day: exudative phase (phase of physiological inflammation)}

Immediately after skin damage, hemostasis is achieved by the formation of a platelet plug. This is followed by the formation of a fibrin matrix, which then becomes the scaffold for infiltrating cells. Only a few hours after injury, lymphocytes, granulocytes and macrophages move into the affected area in order to remove dying tissue and to prevent the formation of infection. This leads to the known local signs of inflammation, i.e., dolor, rubor, calor and tumor. In addition, platelet degranulation is responsible for the release and activation of numerous cytokines, which act as chemotactic agents in the recruitment of inflammatory cells, epithelial cells and fibroblasts. Keloid fibroblasts, as compared to normal skin fibroblasts, have increased expression of many pro-fibrotic growth factors, including transforming growth factor $\beta$ (TGF- $\beta$ ) and platelet-derived growth factor (PDGF). This in turn results in an increased synthesis of collagen, proteoglycans and other extracellular matrix components $(7,8)$.

Thromboxane A2, which is released by platelets, causes vasoconstriction and, consequently, faster hemostasis. Factor X is activated, which converts prothrombin to thrombin. Thrombin in turn converts thrombocyte bonded fibrinogen to fibrin, which closes the wound and forms the above-named provisional matrix for cellular migration. Local swelling at the wound site arises from increased vessel capacity, blood flow to the area and the outflow of fluid, and the leakage of plasma proteins into the surrounding tissue. Vasodilatation is caused by prostaglandin E2, a substance released by granulocytes and macrophages. Local vasodilatation causes a slowing down of the blood flow in capillary vessels. This favours the passage of granulocytes through the capillary vessel walls, which attracts complement and thrombocytic factors. Some of the factors which increase vessel permeability, such as histamine, are also responsible for the local production of pain during the inflammatory process. In the transition to the proliferation phase, macrophages play a key role, continuously synthetizing growth factors [fibroblast growth factor (FGF), TGF- $\alpha$ and $-\beta]$ and cytokines. Macrophages also produce tissue-reducing enzymes (metalloproteinase, elastase and glycooxidase) (7). Proteolysis of the extracelullar matrix is an essential mechanism for angiogenesis as it creates a path for the passage of proliferating and migrating endothelial cells.

\section{Fourth to seventh day: phase of proliferation (i.e., phase of formation of granulation tissue)}

The second phase begins when the invasion of bacteria is arrested and the cell remnants are phagocytosed. It is characterised by the reconstruction of blood vessels, the proliferation of fibroblasts and their formation of collagen, and by the proliferation and migration of keratinocytes, which result in complete wound closure. Furthermore, it seems that histologically normal-appearing keratinocytes interact with fibroblasts to stimulate keloid formation. They achieve this by producing signals that stimulate the fibroblasts in the underlying dermis to proliferate and produce high levels of extracellular matrix (9). Fibrin decomposition products, which are freed during fibrinolysis, also stimulate fibroblasts. The division and concentrated formation of collagen by these connective tissue cells is stimulated by local free PDGF, which is released by thrombocytes and injured endothelial cells (10-12). Due to the increased numbers of fibroblasts and the magnified formation of fibrillar protein, the injured wound begins to heal. However, without the simultaneous occurrence of angiogenesis, the reformation of tissue would be self-limiting. A large number of growth factors have significant angiogenic capabilities. These include PDGF, FGF2, TGF- $\beta$ and vascular endothelial growth factor (VEGF). Currently, ongoing scientific research is identifying the intracellular mediators of angiogenic signals. These include Smad5, a component of the TGF- $\beta$ signaling pathway, and Sox 18, a developmentaly regulated transcription factor. Embryonic Smad5 null mutants do not develop as a result of the failure of proper angiogenesis. Some growth factors, like FGF and PDGF, are connected directly to receptors on endothelial cells, and in this way stimulate the migration and mitosis of vascular endothelial cells. In addition, these same growth factors activate tissue macrophages, thereby releasing FGF, TGF or PDGF. These factors again connect to endothelial tissue and stimulate angiogenesis $(13,14)$. The final phase, known as the 'phase of repair', consists of filling up of the wound with connective tissue. The remodelling of the scar occurs during the phase of repair. Keratinocytes proliferate at the edge of the wound and move into the wounded area. The newly produced epithelial tissue covers the wounded area through the production of fibroblasts and factors involved in angiogenesis in a temporally and spatially coordinated manner. Keratocyte growth factor (KGF) and epidermal growth factor (EGF) are growth factors that disburb the attachment of epidermial keratinocytes to the bottom of the wound, simultaneously accelerating their division (15). EGF is believed to be responsible for the acceleration and maturation of the epithelium, and is an important modulator of differentiation and the repair of epidermal structures. Most endothelial cells, macrophages and fibroblasts undergo apoptosis or exit the wound. It is known that the regulation of apoptosis and proliferation is altered in keloids $(16,17)$. Keloid fibroblasts have been shown to have a lower rate of apoptosis than normal skin fibroblasts (18). The temporary scar mostly consists of collagen and extracellular matrix. Within one year the acellular matrix is actively remodelled from a mainly type III collagen backbone to one predominantly composed of type I collagen (19). This process is carried out by the above-mentioned matrix metalloproteinases, which are secreted by fibroblasts, macrophages and endothelial cells (20). 


\section{Classification of scars}

Discrimination between different types of scars is possible and necessary, but can be difficult as scars are constantly changing their features during maturation. The most commonly noted features are: mass, texture, outline, pigmentation, structure, elasticity, toughness, distortion, the scar's bearing to the relaxed skin tension lines (RSTL), and finally its activity and the degree to which it matures. For research and therapy purposes, an ability to discriminate between types of scars is extremely useful. In light of this, different scaling methods have been proposed, such as the Vancouver scar scale, the visual analogic scale, the patient and observer scale and the Manchester scale. However, these various scales are still under discussion regarding their accuracy, as each scale has an element of subjectivity, leading to errors in classification (21-23) and the inability to reproduce identical data from either the same individual or between individuals. Some attributes, like elasticity, can be measured by technical aids, but not all features of a scar are measurable in this way. In conclusion, the ideal scaling system has not yet been proposed. For the purpose of this review, it is important to distinguish between hypertrophic and keloid scars, as inappropriate management of either can lead to recurrence and larger scars.

\section{Incidence of keloids}

Keloids mainly occur upon the sternum, the ear lobe, the upper back and the neck. Additionally, increased skin tension in the wound appears to promote keloid formation. Of note is the regressing of keloids initially located on the sternum once this skin has been transplanted to another region of the body. Keloids are more prevalent in highly pigmented skin and in women, although slightly less so in the latter. There have also been reported cases of increased keloids growth during pregnancy (24-26). Such preferences of localisation, race and gender are not seen in hypertrophic scars. However, both keloid and hypertrophic scars are found in all age groups, although both are observed slightly more often in younger age groups, especially those undergoing puberty (27). Earrings, piercings and areas where the individual has been vaccinated all appear to increase the incidence of keloids (28). Equally, skin diseases like acne or severe burns are linked with keloid formation, as are areas of insect bites. However, cases have been reported of the spontaneous occurrence of keloids. In view of these clinical observations, several theories regarding the aetiology of keloids have been developed in reference to skin tension, the influence of the melanocyte, gender, hormones, and injury to the skin.

\section{Histology of keloids}

Due to changes occurring during maturation, histological discrimination between hypertrophic scars and keloids is as difficult as their clinical differentiation. Bundles of collagen positioned in thick strings, parallel to the thickened dermis, are considered the key histological feature of keloids (29). Keloid scars are noted as having less proteoglycan content than hypertrophic scars, and do not show the distinctive feature of collagen type I being replaced by type III, which is seen in hypertrophic scars (30). In its center, a keloid has fewer cells and, in contrast to hypertrophic scars, does not contain $\alpha$-actin-positive smooth musculature featuring myofibroblasts (31). Furthermore, the keloid epidermic layer contains increased amounts of hyaluronic acid, which is an essential part of the epidermis of young scars (32). The presence of apoptosis in keloids is reduced, and ATP-levels are increased in comparison to hypertrophic scars (33). Additionally, keloid fibroblasts express more matrix metalloproteinase than normal skin fibroblasts (34).

\section{Growth factors and cytokines}

As growth factors are the main topic of our research, the focus is on these peptides in the present review. Both cytokines and growth factors are crucial for the initialisation, the feeding and the regulation of the body's response to injury (4). Cytokines, expressed by numerous cell types, are members of a family of molecules that have autocrine, paracrine and endocrine effects $(4,35)$. Autocrine communication means that a cell signals to itself. In paracrine signalling, the cell signals its immediate neighbours, whereas in endocrine signalling the communication is between distant cells via the bloodstream. Growth factors are defined as peptide mediators involved in cell cycling, growth and proliferation, as well as in intercellular communication and apoptosis. The terms growth factor and cytokine do not have biological significance, but rather represent how these molecules were historically defined. Signalling proteins were traditionally called cytokines when they are expressed during the inflammatory phase of healing, and were called growth factors when they are expressed in later phases. Both cytokines and growth factors are seen in wound healing as well as in abnormal wound healing, abnormal scarring and chronic skin diseases (6). Growth factors are polypeptide signalling molecules that attach to specific membrane-attached receptors and activate them. This in turn activates an intracellular pathway, which goes on to regulate gene expression and the cycle of cell progression. Growth factors are a major component of the process of wound healing as they are involved in cell infiltration, cell proliferation, matrix deposition and scar formation. In view of this, it is of no surprise that their dysregulation has been implicated in the pathogenesis of fibrosis. There is a need for high levels of growth factors and cytokines as key regulators during the healing process, but abnormal growth factor expression may lead to keloids. It is possible that the timing and pattern of cytokine response may be more important than the magnitude of their expression (35). In the last two decades, an increased and accelerated level of knowledge on growth factors, particularly in wound healing, has been reached. However, it is beyond the scope of this article to explore this background knowledge.

Vascular endothelial growth factor. Vascular endothelial growth factor (VEGF) is secreted by keratinocytes, macrophages and fibroblasts (36-38) and is induced by the local tissue environment, such as hypoxia or nitric oxide production. The production of VEGF steadily increases post injury. It is a potent angiogenic factor and is important for the production, differentiation and permeability of blood vessels and lymphatic endothelial cells. VEGF was first described as a mediator of vascular permeability in the late 1970's (39). It is 
a key factor for the survival of human endothelial cells due to the anti-apoptotic effect it has on these cells. VEGF acts via tyrosine kinase receptors located predominantly in endothelial cells (40).

Transforming growth factor $\beta$. Transforming growth factor $\beta$ (TGF- $\beta$ ) is released by platelets, macrophages and fibroblasts. This factor, like VEGF, is a key component in wound healing. TGF- $\beta$ is a member of a large family of structurally-related factors with varying activities and is found in three isomers, 1-3, whose most important activities include fibroblast migration, maturation and the synthesis of extracellular matrix (41). Specifically, TGF- $\beta 1$ appears to play an important role in the metabolism of collagen (42). TGF is potentially an inhibitor of epithelial cell proliferation as it blocks the G1-phase in the eukaryotic cell cycle $(43,44)$ and promotes angiogenesis $(45,46)$. TGF exists in most cell types, especially in thrombocytes. Isoforms 1-3 have varying effects depending on the cell type in which they are found. Antidromic effects are possible in cell proliferation and differentiation (47). It is reported that TGF- $\beta 1$ and $-\beta 2$ are pro-fibrotic and that TGF- $\beta 3$ is anti-fibrotic (48). As such, the influence of TGF- $\beta$ on scarring is related to its overexpression, in the case of TGF- $\beta 1$ or $-\beta 2$, and to the proportion of TGF isomers involved. In experiments with rats, the neutralisation of TGF- $\beta 1$ and $-\beta 2$ by antibodies combined with the activation of TGF- $\beta 3$ has prevented the formation of scar tissue (50). By transforming fibroblasts, the fibroblasts lose their cellular mounting and then proliferate uninhibited. TGF- $\beta 1$ stimulates VEGF (51), decreases matrix metalloproteinase activity and increases the activity of endogenous inhibitors of matrix metalloproteinase expression, which may favour collagen accumulation and scarring (45). TGF- $\beta$ also induces connective tissue growth factor, which leads to cutaneous fibrosis in pathological conditions. Connective tissue growth factor (CTGF) is diffusely active within keloids and other skin fibroses, such as scleroderma, systemic sclerosis and Dupuytren's contracture (52). Comparing wound healing in adult skin with fetal skin, Ferguson et al showed that levels of TGF- $\beta 1$ and $-\beta 2$ and PDGF are decreased in fetal skin, while the level of TGF- $\beta 3$ is increased (53).

Epidermal growth factor. Epidermal growth factor (EGF) is secreted by keratinocytes and belongs to a group of growth factors including TGF- $\alpha$ and hepatocyte growth factor/scatter factor $(\mathrm{HGF} / \mathrm{SF})$. TGF- $\alpha$ and $\mathrm{EGF}$ compete for the EGF receptor, which is found on adult cells, with the exception of haematopoietic cells. EGF stimulates epithelial proliferation, increases fibroblast collagenase secretion and inhibits fetal wound contraction $(15,16)$. TGF- $\alpha$ stimulates epithelial cell proliferation, but is also capable of inhibiting epithelial proliferation, depending on the specific target cell (41). Its most important function is its role in developing anti-tumor monoclonal antibodies (54).

Platelet-derived growth factor. Platelet-derived growth factor (PDGF) is produced by platelets, macrophages, vascular endothelium, fibroblasts and keratinocytes, all of which are cells involved in early wound healing $(9,12)$. PDGF is released by platelets soon after injury, and recruits fibroblasts and macrophages. It is also secreted by macrophages and stimulates collagen and proteoglycan synthesis. PDGF is involved in all stages of wound healing. It is a dimer consisting of two polypeptides, chains $\mathrm{A}$ and $\mathrm{B}$, and occurs as three isomers, $\mathrm{AA}, \mathrm{AB}$ and $\mathrm{BB}$, with two receptors, $\alpha$ and $\beta$. These receptors act antagonistically $(55,56)$; for example, the activation of $\alpha$-receptor inhibits the chemotaxis of fibroblasts while the activation of $\beta$-receptor increases the chemotaxis of fibroblasts. PDGF influences the growth and function of various mesenchymal cells. It is found in high concentrations in thrombocytes and within the serum, and is mitogenous and chemotactic for connective tissue cells and smooth muscle cells within blood vessels. Furthermore, PDGF stimulates the production of collagenase and the components of the extracellular matrix, fibronectin and hyaluronic acid (57). Pierce et al reported that all three PDGF isomers are found in extremely low levels in normal skin and in chronic nonhealing ulcers (58). In contrast to VEGF, PDGF has a prolonged expression during scar formation, but disappears quickly in fetal wounds (59). VEGF expression increases 2-fold in scarless wounds, while its expression remains unchanged in fetal wounds (60).

Fibroblast growth factor. Fibroblast growth factors (FGF) are a family of approximately 20 heparin-binding growth factors. FGFs are produced by fibroblasts, endothelial cells, smooth muscle cells, chondrocytes and mast cells, and are secreted by macrophages and endothelial cells in wounds (61). FGF induces angiogenesis and epithelialisation through the induction of fibroblast and keratinocyte proliferation and migration, endothelial cell growth and migration, and collagen remodelling. FGF additionally prevents wound contraction (62). FGF7, also called keratocyte growth factor (KGF), is the best known member of the group, responsible for keratinocyte regulation and maturation. Other members include acidic FGF (aFGF) and basic FGF (bFGF). One member shares a receptor with heparin. Heparin prevents aFGF from deactivating. FGF family members enhance the duplication and differentiation of many mesenchymal cells, including fibroblasts, muscle cells and chondrocytes. PDGF decreases the ability of the receptor to bond bFGF.

Hepatocyte growth factor/scatter factor. Hepatocyte growth factor/scatter factor (HGF/SF) is secreted by vascular smooth muscle cells and fibroblasts. HGF was originally identified in 1984 as a mitogen of primary cultured hepatocytes (63). SF was identified in 1985 as a fibroblast-derived epithelial motility factor. Subsequent characterisation revealed SF to be identical to HGF, with C-Met as the receptor $(64,65)$. HGF/SF induces the expression and synthesis of matrix metalloproteinases. It enhances endothelial cell survival and renders vascular endothelial cells resistant to apoptosis. By increasing the expression of VEGF, angiogenesis is also increased. Sengupta et al showed that angiogenesis was possible without VEGF by means of the direct activation of the extracellular receptors Akt and Erk (66). Abounder et al demonstrated C-Met's decisive role in the growth of brain tumors due to its influence on angiogenesis (67). HGF/SF is produced by activated fibroblasts and increases the expression of VEGF in keratinocytes. As such, it has an important role in wound healing. Zhu et al induced the overexpression of HGF in vascular smooth muscle 
cells. This led to the increased migration and proliferation of endothelial cells, thus demonstrating the crucial role of HGF in the re-epithelialisation of injured blood vessels (68). We can now demonstrate the presence of modified HGF/SF expression in normal and radiated skin and in keloids. The strongest expression was found in keloids, whereas the lowest expression was found in radiated skin. Naim et al showed that TGF- $\beta 1$ and HGF/SF increase the expression of VEGF. Therefore, $\mathrm{HGF} / \mathrm{SF}$ and TGF- $\beta 1$ have opposite functions.

\section{Fundamentals of prevention and therapy}

Despite numerous studies, the pathogenesis of keloids remains unclear.

Prevention techniques. The suturing technique one should adopt involves as little trauma to the skin as possible, with everted wound edges and infection prophylaxis. Marginal skin tension in the wound, for example by bringing the suture along the RSTL or by infiltration of botulinum toxin intra or post-operatively in the adjacent musculature, is important (69) and undoubtedly results in a better cosmetic result. Often, the application of this suturing technique leads to a scar resembling a fine line with normal pigmentation and without anomalies of the outline, distorsions or contractures. However, to completely prevent keloid formation using this method is impossible.

Therapy. Depending on the point of therapeutic procedure within the scar, several therapy modalities have been suggested (70): i) application techniques, such as compression bandages and silicon sheets (71); ii) injection techniques with, for example, corticosteroid, or with substances such as 5-fluorouracil, interferons, bleomycin, verapamil, penicillamine and colchicines (72-74); iii) partial resection techniques, such as cryotherapy, or resection by carbon dioxide laser $\left(\mathrm{CO}_{2}\right)$ or $\mathrm{Nd}$ :Yag-laser (75-77); iv) resection techniques, such as WZ- and VY-plastic surgery; v) radiation of keloids, which is also quite common, with a reported cumulative dose of 2-30 Gy (78-80).

The relapse frequency after surgery is noted as being between 45 and $100 \%$. An improved chance of avoiding recurrence is occasionally observed following the combination of resection techniques with any of the other techniques, in particular radiation, post-operatively. However, a $100 \%$ rate of avoiding relapse is not achievable by any of the techniques. In summary, the current schemes of prevention and therapy of keloids are empirical, with few being reliable. Additionally, the therapy is associated with a high rate of relapse.

\section{Prospects}

It is becoming increasingly obvious, due to the failure of the above-mentioned treatment options, that the crux of the problem confronting keloids is the lack of scientific understanding regarding their aetiology. It is important to recognise the likelihood that a number of growth factors and cytokines involved in keloid formation have not yet been identified. It is assumed that the timing and pattern of the growth factor and cytokine response may be more important than the magnitude of their expression (35). However, little research has been conducted in this area. Furthermore, it is understood that not all interactions between growth factors and cytokines are fully understood. However, the above-mentioned experiments involving opposing and antagonistic growth factors and antibodies suggest that this might be an area worth investigating in regards to the treatment and prevention of keloids.

To date, though, the clinical success of topical growth factor protein application has been limited. There are several reasons why growth factors are limited in clinical use: the application of a single growth factor might have only a transient effect. Proteolytic enzymes in the wound exudates tend to lyse topically applied growth factors. Furthermore, the final diffusion into the wound tissue of the active protein, which remains on the wound bed after these interactions, is predictably low. On the other hand, systemic administration may cause severe systemic reactions. For this reason, gene therapy appears increasingly promising.

Gene therapy is normally defined as the treatment of hereditary genetic failures and the resulting defects in metabolic key functions. It requires the exact knowledge and localisation of relevant genes involved in the metabolic process. To date, genetic analysis research has not led to the identification of any single gene that might be the causative agent in the formation of keloids (81). Therefore, in wound healing, with its many different interlinked cell types and mediators working together simultaneously and within different layers of the skin, gene analysis is unlikely to be a solution in the immediate future.

Another possibility for gene therapy of the skin is so-called somatic gene therapy. This implies the direct introduction of DNA into tissue (82). The skin is an ideal candidate for such genetic manipulations; it is easily accessible, and is therefore easy to transfect with genetic material and to monitor for adverse reactions. The epidermis has a high turnover rate, which is an ideal environment for most gene transfer methods. The predominant cells of the skin, fibroblasts and keratinocytes, are readily harvested and cultured (83). The gene delivery system is called a vector. A distinction is drawn between virusdependent (transduction) and virus-independent (transfection) gene transfer. Both can be carried out in vivo, whereby genes are delivered directly to target cells, or in vitro, in which cells are removed from the tissue, genetically modified, and implanted back into the donor tissue. Transduction techniques are performed using recombinant adenoviruses, adeno-associated viruses, retroviruses and the recombinant herpes simplex viruses. However, viral infection-associated toxicity, immunological compromise and possible mutagenetic or carcinogenic effects make this approach potentially dangerous. The transfection techniques employed are direct injection, transfection with liposomes (lipofection), electroporation, particle bombardement (gene-gun) and antisense oligonuleotide delivery. The key benefits of these techniques are the ability to package relatively large amounts of genetic material and introduce it with low immunogenicity. Their disadvantages are non-specific targeting and low efficiency, which necessitates repeated treatments. However, this last disadvantage is a welcome attribute in wound treatment, since the termination of the gene effect is desirable after the completion of the healing process. Non-viral gene delivery is easy, simple, direct, inexpensive and does not require in vitro manipulation. Nevertheless, among these techniques, the optimal delivery system has not yet been identified (84). Most current research involving gene therapy and wound 
healing is specific to chronic non-healing wounds, and is rarely related to keloid formation. However, there is an increasing understanding of dysregulation in growth factor and cytokine expression and their link to keloid formation. Based on these findings, modern targeted gene therapy is the most promising treatment approach for cutaneous wound healing.

\section{References}

1. Robert R, Meyer W, Bishop S, Rosenberg L, Murphy L and Blakeney P: Disfiguring burn scars and adolescent self-esteem. Burns 25: 581-585, 1999.

2. Dorfmuller M: Psychological management and after-care of severely burned patients. Unfallchirurg 98: 213-217, 1995.

3. Bennett NT and Schultz GS: Growth factors and wound healing: biochemical properties of growth factors and their receptors. Am J Surg 165: 728-737, 1993.

4. Bennett NT and Schultz GS: Growth factors and wound healing: Part II. Role in normal and chronic wound healing. Am J Surg 166: 74-81, 1993.

5. Grazul-Bilska AT, Johnson ML, Bilski JJ, Redmer DA, Reynolds LP, Abdullah A and Abdullah KM: Wound healing: the role of growth factors. Drugs Today 39: 787-800, 2003.

6. Werner Sand Grose R: Regulation of wound healing by growth factors and cytokines. Physiol Rev 83: 835-870, 2003.

7. Hunt TK, Knighton DR, Thakral KK, Goodson WH III and Andrews WS: Studies on inflammation and wound healing: angiogenesis and collagen synthesis stimulated in vivo by resident and activated wound macrophages. Surgery 96: 48-54, 1984.

8. Xia W, Longaker MT and Yang GP: P38 MAP kinase mediates transforming growth factor- $\beta$ transcription in human keloid fibroblasts. Am J Physiol Regul Integr Comp Physiol 290: R501-R508, 2006.

9. Haisa M, Okochi H and Grotendorst GR: Elevated levels of PDGF alpha receptors in keloid fibroblasts contribute to an enhanced response to PDGF. J Invest Dermatol 103: 560-563, 1994.

10. Lim IJ, Phan TT, Song C, Tan WT and Longaker MT: Investigation of the influence of keloid-derived keratinocytes on fibroblast growth and proliferation in vitro. Plast Reconstr Surg 107: 797-808, 2001.

11. Seifert RA, Coats SA, Raines EW, Ross R and Bowen-Pope DF: Platelet-derived growth factor (PDGF) receptor $\alpha$-subunit mutant and reconstituted cell lines demonstrate that transforming growth factor- $\beta$ can be mitogenic through PDGF A-chain-dependent and -independent pathways. J Biol Chem 269: 13951-13955, 1994.

12. Ross R, Raines EW and Bowen-Pope DF: The biology of plateletderived growth factor. Cell 46: 155-169, 1986.

13. Hom DB and Maisel RH: Angiogenic growth factors: their effects and potential in soft tissue wound healing. Ann Otol Rhinol Laryngol 101: 349-354, 1992.

14. Yang X, Castilla LH, Xu X, Li C, Gotay J, Weinstein M, Liu PP and Deng CX: Angiogenesis defects and mesenchymal apoptosis in mice lacking SMAD5. Development 126: 1571-1580, 1999.

15. Gibbs S, Silva Pinto AN, Murli S, Huber M, Hohl D and Ponec M: Epidermal growth factor and keratinocyte growth factor differentially regulate epidermal migration, growth and differentiation. Wound Repair Regen 8: 192-203, 2000.

16. Ishikawa T, Terai H and Kitajima T: Production of a biologically active epidermal growth factor fusion protein with high collagen affinity. J Biochem 129: 627-633, 2001

17. Nirodi CS, Devalaraja R, Nanney LB, Arrindell S, Russell S, Trupin J and Richmond A: Chemokine and chemokine receptor expression in keloid and normal fibroblasts. Wound Repair Regen 8: 371-382, 2000.

18. Mustoe TA, Cooter RD, Gold MH, Hobbs FD, Ramelet AA, Shakespeare PG, Stella M, Teot L, Wood FM and Ziegler UE: International clinical recommendations on scar management. Plast Reconstr Surg 110: 560-571, 2002.

19. Lovvorn HN III, Cheung DT, Nimni ME, Perelman N, Estes JM and Adzick NS: Relative distribution and crosslinking of collagen distinguish fetal from adult sheep wound repair. J Pediatr Surg 34: 218-223, 1999.

20. Levenson SM, Geever EF, Crowley LV, Oates JF III, Berard CW and Rosen H: The healing of rat skin wounds. Ann Surg 161: 293-308, 1965.

21. Nedelec B, Shankowsky HA and Tredget EE: Rating the resolving hypertrophic scar: comparison of the Vancouver Scar Scale and scar volume. J Burn Care Rehabil 21: 205-212, 2000.
22. Roques $\mathrm{C}$ and Teot L: A critical analysis of measurements used to assess and manage scars. Int J Low Extrem Wounds 6: 249-253, 2007.

23. Baryza MJ and Baryza GA: The Vancouver Scar Scale: an administration tool and its interrater reliability. J Burn Care Rehabil 16: 535-538, 1995.

24. BayatA,Arscott G, OllierWE, Ferguson MW and McGrouther DA: Description of site-specific morphology of keloid phenotypes in an Afrocaribbean population. Br J Plast Surg 57: 122-133, 2004.

25. Child FJ, Fuller LC, Higgins EM and Du Vivier AW: A study of the spectrum of skin disease occurring in a black population in south-east London. Br J Dermatol 141: 512-517, 1999.

26. English RS and Shenefelt PD: Keloids and hypertrophic scars. Dermatol Surg 25: 631-638, 1999.

27. Brissett AE and Sherris DA: Scar contractures, hypertrophic scars and keloids. Facial Plast Surg 17: 263-272, 2001.

28. Atiyeh BS, Costagliola M and Hayek SN: Keloid or hypertrophic scar: the controversy: review of the literature. Ann Plast Surg 54: 676-680, 2005.

29. Kischer CW and Brody GS: Structure of the collagen nodule from hypertrophic scars and keloids. Scan Electron Microsc: 371-376, 1981.

30. Scott PG, Dodd CM, Tredget EE, Ghahary A and Rahemtulla F: Chemical characterization and quantification of proteoglycans in human post-burn hypertrophic and mature scars. Clin Sci 90: 417-425, 1996.

31. Nedelec B, Shankowsky H, Scott PG, Ghahary A and Tredget EE: Myofibroblasts and apoptosis in human hypertrophic scars: the effect of interferon- $\alpha 2 b$. Surgery 130: 798-808, 2001.

32. Bertheim U and Hellstrom S: The distribution of hyaluronan in human skin and mature, hypertrophic and keloid scars. Br J Plast Surg 47: 483-489, 1994.

33. Sayah DN, Soo C, Shaw WW, Watson J, Messadi D, Longaker MT, Zhang $\mathrm{X}$ and Ting K: Down-regulation of apoptosis-related genes in keloid tissues. J Surg Res 87: 209-216, 1999.

34. Fujiwara M, Muragaki Y and Ooshima A: Keloid-derived fibroblasts show increased secretion of factors involved in collagen turnover and depend on matrix metalloproteinase for migration. Br J Dermatol 153: 295-300, 2005.

35. Rumalla VK and Borah GL: Cytokines, growth factors and plastic surgery. Plast Reconstr Surg 108: 719-733, 2001.

36. Frank S, Stallmeyer B, Kampfer H, Kolb N and Pfeilschifter J: Nitric oxide triggers enhanced induction of vascular endothelial growth factor expression in cultured keratinocytes $(\mathrm{HaCaT})$ and during cutaneous wound repair. FASEB J 13: 2002-2014, 1999.

37. Nissen NN, Polverini PJ, Koch AE, Volin MV, Gamelli RL and DiPietro LA: Vascular endothelial growth factor mediates angiogenic activity during the proliferative phase of wound healing. Am J Pathol 152: 1445-1452, 1998.

38. Shweiki D, Itin A, Soffer D and Keshet E: Vascular endothelial growth factor induced by hypoxia may mediate hypoxia-initiated angiogenesis. Nature 359: 843-845, 1992.

39. Iruela-Arispe ML and Dvorak HF: Angiogenesis: a dynamic balance of stimulators and inhibitors. Thromb Haemost 78: 672-677, 1997.

40. Neufeld G, Cohen T, Gengrinovitch S and Poltorak Z: Vascular endothelial growth factor (VEGF) and its receptors. FASEB J 13: 9-22, 1999.

41. Schultz G, Rotatori DS and Clark W: EGF and TGF- $\alpha$ in wound healing and repair. J Cell Biochem 45: 346-352, 1991.

42. Buckmire MA, Parquet G, Greenway S and Rolandelli RH: Temporal expression of TGF- $\beta 1$, EGF and PDGF-BB in a model of colonic wound healing. J Surg Res 80, 52-57, 1998.

43. Massague J: TGF- $\beta$ in Cancer. Cell 134: 215-230, 2008.

44. Massague $J$ and Gomis RR: The logic of TGF- $\beta$ signaling. FEBS Lett 580: 2811-2820, 2006.

45. Roberts AB, Sporn MB, Assoian RK, Smith JM, Roche NS, Wakefield LM, Heine UI, Liotta LA, Falanga V, Kehrl JH, et al: Transforming growth factor type $\beta$ : rapid induction of fibrosis and angiogenesis in vivo and stimulation of collagen formation in vitro. Proc Natl Acad Sci USA 83: 4167-4171, 1986.

46. Roberts AB, Flanders KC, Heine UI, Jakowlew S, Kondaiah P, Kim SJ and Sporn MB: Transforming growth factor- $\beta$ : multifunctional regulator of differentiation and development. Philos Trans R Soc Lond B Biol Sci 327: 145-154, 1990.

47. Kaklamani VG and Pasche B: Role of TGF- $\beta$ in cancer and the potential for therapy and prevention. Expert Rev Anticancer Ther 4: 649-661, 2004

48. Colwell AS, Yun R, Krummel TM, Longaker MT and Lorenz HP: Keratinocytes modulate fetal and postnatal fibroblast transforming growth factor- $\beta$ and Smad expression in co-culture. Plast Reconstr Surg 119: 1440-1445, 2007. 
49. Dang CM, Beanes SR, Soo C, Ting K, Benhaim P, Hedrick MH and Lorenz HP: Decreased expression of fibroblast and keratinocyte growth factor isoforms and receptors during scarless repair. Plast Reconstr Surg 111: 1969-1979, 2003.

50. Shah M, Foreman DM and Ferguson MW: Neutralisation of TGF- $\beta 1$ and TGF- $\beta 2$ or exogenous addition of TGF- $\beta 3$ to cutaneous rat wounds reduces scarring. J Cell Sci 108: 985-1002, 1995.

51. Wang L, Kwak JH, Kim SI, He Y and Choi ME: Transforming growth factor- $\beta 1$ stimulates vascular endothelial growth factor 164 via mitogen-activated protein kinase kinase 3-p38 $\alpha$ and p38d mitogen-activated protein kinase-dependent pathway in murine mesangial cells. J Biol Chem 279: 33213-33219, 2004.

52. Polo M, Smith PD, Kim YJ, Wang X, Ko F and Robson MC: Effect of TGF- $\beta 2$ on proliferative scar fibroblast cell kinetics. Ann Plast Surg 43: 185-190, 1999.

53. Ferguson MW and O'Kane S: Scar-free healing: from embryonic mechanisms to adult therapeutic intervention. Philos Trans R Soc Lond B Biol Sci 359: 839-850, 2004.

54. Christensen ME: The EGF receptor system in head and neck carcinomas and normal tissues. Immunohistochemical and quantitative studies. Dan Med Bull 45: 121-134, 1998.

55. Lepisto J, Peltonen J, Vaha-Kreula M, Soderstrom K, Niinikoski J and Laato M: Selective modulation of collagen gene expression by different isoforms of platelet-derived growth factor in experimental wound healing. Cell Tissue Res 286: 449-455, 1996.

56. Beer HD, Longaker MT and Werner S: Reduced expression of PDGF and PDGF receptors during impaired wound healing. J Invest Dermatol 109: 132-138, 1997.

57. Li L, Asteriou T, Bernert B, Heldin CH and Heldin P: Growth factor regulation of hyaluronan synthesis and degradation in human dermal fibroblasts: importance of hyaluronan for the mitogenic response of PDGF-B. Biochem J 404: 327-336, 2007.

58. Pierce GF, Tarpley JE, Tseng J, Bready J, Chang D, Kenney WC, Rudolph R, Robson MC, Vande BJ, Reid P, et al: Detection of platelet-derived growth factor (PDGF)-AA in actively healing human wounds treated with recombinant PDGF-BB and absence of PDGF in chronic nonhealing wounds. J Clin Invest 96: 1336-1350, 1995.

59. Whitby DJ and Ferguson MW: Immunohistochemical localization of growth factors in fetal wound healing. Dev Biol 147: 207-215, 1991.

60. Soo C, Hu FY, Zhang X, Wang Y, Beanes SR, Lorenz HP, Hedrick MH, Mackool RJ, Plaas A, Kim SJ, Longaker MT, Freymiller E and Ting K: Differential expression of fibromodulin, a transforming growth factor- $\beta$ modulator, in fetal skin development and scarless repair. Am J Pathol 157: 423-433, 2000.

61. Reed JA, Albino AP and McNutt NS: Human cutaneous mast cells express basic fibroblast growth factor. Lab Invest 72: 215-222, 1995.

62. Hsu M, Peled ZM, Chin GS, Liu W and Longaker MT: Ontogeny of expression of transforming growth factor- $\beta 1$ (TGF- $\beta 1$ ), TGF- $\beta 3$ and TGF- $\beta$ receptors I and II in fetal rat fibroblasts and skin. Plast Reconstr Surg 107: 1787-1794, 2001.

63. Nakagami H, Morishita R, Yamamoto K, Taniyama Y, Aoki M, Matsumoto K, Nakamura T, Kaneda Y, Horiuchi M and Ogihara T: Mitogenic and antiapoptotic actions of hepatocyte growth factor through ERK, STAT3 and AKT in endothelial cells. Hypertension 37: 581-586, 2001.

64. Furlong RA, Takehara T, Taylor WG, Nakamura T and Rubin JS : Comparison of biological and immunochemical properties indicates that scatter factor and hepatocyte growth factor are indistinguishable. J Cell Sci 100: 173-177, 1991.

65. Bottaro DP, Rubin JS, Faletto DL, Chan AM, Kmiecik TE, Vande Woude GF and Aaronson SA: Identification of the hepatocyte growth factor receptor as the c-met proto-oncogene product. Science 251: 802-804, 1991
66. Sengupta S, Gherardi E, Sellers LA, Wood JM, Sasisekharan R and Fan TP: Hepatocyte growth factor/scatter factor can induce angiogenesis independently of vascular endothelial growth factor. Arterioscler Thromb Vasc Biol 23: 69-75, 2003.

67. Abounader R and Laterra J: Scatter factor/hepatocyte growth factor in brain tumor growth and angiogenesis. Neuro Oncol 7: 436-451, 2005.

68. Zhu G, Huang L, Song M, Yu Z, Wu X, Zhao X, Jin J, Zhao G, Chen J and Yu S: Overexpression of hepatocyte growth factor in smooth muscle cells regulates endothelial progenitor cells differentiation, migration and proliferation. Int J Cardiol, 16 Dec 2008, E-pub ahead of print.

69. Gassner HG, Brissett AE, Otley CC, Boahene DK, Boggust AJ, Weaver AL and Sherris DA: Botulinum toxin to improve facial wound healing: A prospective, blinded, placebo-controlled study. Mayo Clin Proc 81: 1023-1028, 2006.

70. Kelly AP: Medical and surgical therapies for keloids. Dermatol Ther 17: 212-218, 2004.

71. Dockery GL and Nilson RZ: Treatment of hypertrophic and keloid scars with SILASTIC Gel Sheeting. J Foot Ankle Surg 33: 110-119, 1994.

72. Sclafani AP, Gordon L, Chadha M and Romo T III: Prevention of earlobe keloid recurrence with postoperative corticosteroid injections versus radiation therapy: a randomized, prospective study and review of the literature. Dermatol Surg 22: 569-574, 1996.

73. Darzi MA, Chowdri NA, Kaul SK and Khan M: Evaluation of various methods of treating keloids and hypertrophic scars: a 10-year follow-up study. Br J Plast Surg 45: 374-379, 1992.

74. Dalkowski A, Fimmel S, Beutler C and Zouboulis C: Cryotherapy modifies synthetic activity and differentiation of keloidal fibroblasts in vitro. Exp Dermatol 12: 673-681, 2003.

75. Haurani MJ, Foreman K, Yang JJ and Siddiqui A: 5-Fluorouracil treatment of problematic scars. Plast Reconstr Surg 123: 139-148, 2009.

76. Sherman R and Rosenfeld H: Experience with the Nd:YAG laser in the treatment of keloid scars. Ann Plast Surg 21: 231-235, 1988.

77. Norris JE: The effect of carbon dioxide laser surgery on the recurrence of keloids. Plast Reconstr Surg 87: 44-49, 1991.

78. Wagner W, Alfrink M, Micke O, Schafer U, Schuller P and Willich N: Results of prophylactic irradiation in patients with resected keloids-a retrospective analysis. Acta Oncol 39: 217-220, 2000.

79. Kutzner J, Schneider L and Seegenschmiedt MH: Radiotherapy of keloids. Patterns of care study-results. Strahlenther Onkol 179: 54-58, 2003

80. Viani GA, Stefano EJ, Afonso SL and De Fendi LI: Postoperative strontium-90 brachytherapy in the prevention of keloids: results and prognostic factors. Int J Radiat Oncol Biol Phys 7: 1510-1516, 2009.

81. Marneros AG, Norris JE, Watanabe S, Reichenberger E and Olsen BR: Genome scans provide evidence for keloid susceptibility loci on chromosomes $2 \mathrm{q} 23$ and $7 \mathrm{p} 11$. J Invest Dermatol 122: 1126-1132, 2004.

82. Levy RJ, Goldstein SA and Bonadio J: Gene therapy for tissue repair and regeneration. Adv Drug Deliv Rev 33: 53-69, 1998.

83. Branski LK, Pereira CT, Herndon DN and Jeschke MG: Gene therapy in wound healing: present status and future directions. Gene Ther 14: 1-10, 2007.

84. Jeschke MG, Herndon DN, Baer W, Barrow RE and Jauch KW: Possibilities of non-viral gene transfer to improve cutaneous wound healing. Curr Gene Ther 1: 267-278, 2001. 